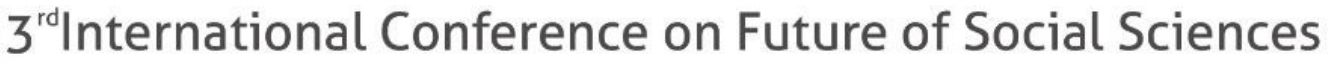 \\ 5 - 7 March 2021 \\ BERLIN, GERMANY
}

\section{Male Offenders of Domestic Sex Trafficking: A Multi-Case Study}

\author{
Bekken, F.F..$^{*}$, Simons, E.I. ${ }^{2}$, Van Rij, J. ${ }^{3} \&$ Noteboom, F. ${ }^{4}$ \\ ${ }^{1}$ Research associate CKM and Fier, the Netherlands \\ ${ }^{2}$ Research associate CKM, the Netherlands \\ ${ }^{3}$ Senior Researcher Netherlands National Police, the Netherlands \\ ${ }^{4}$ Head of CKM, the Netherlands / Germany \\ *Corresponding author
}

\begin{abstract}
While ample studies have focused on victims of sex trafficking or on the modus operandi of traffickers, a knowledge gap exists where sex traffickers are concerned. Studies that investigated sex traffickers, mostly made no distinction between domestic and cross-border traffickers and made no distinction based on gender. However, differences between traffickers of several forms of trafficking and gender appear in the literature. The aim of this multi-case study was to investigate the background of domestic male sex traffickers of female juvenile and adolescent victims, so as to be able to provide a detailed description of this group. For that purpose, 25 police files of convicted traffickers were analyzed and several themes regarding demographics, socioeconomic status, psychosocial background and criminal carrier were described. When traffickers operated in networks, the size, structure and composition of the networks are described. In the discussion, the results of the study are compared to earlier studies, and based on a synthesis of the data, a detailed profile of domestic sex traffickers and their networks, as well as suggestions for future research, is provided.
\end{abstract}

Keywords: Domestic sex trafficking; sexual exploitation; Juvenile and adolescent victims, Criminal Networks

\section{Introduction}

Human trafficking is a serious crime and a grave violation of human rights (UNODC). Worldwide, the majority of victims of human trafficking are subjected to sexual exploitation, however the exact number of victims cannot be given: the detected victims (and prosecuted traffickers) are considered to be the proverbial 'tip of the iceberg' (UNODC). The Dutch Rapporteur on Trafficking in Human Beings and Sexual Violence Against Children (next: Dutch Rapporteur) also found that sex trafficking is the most prevalent form of human trafficking in the Netherlands. Between 2015 and 2019 almost 5.100 victims of human trafficking in the Netherlands were registered, of which six out of ten (known) victims were sexually exploited (Dutch Rapporteur, 2020). Eight out of ten victims of sexually exploited victims were female (Dutch Rapporteur, 2020). These victims are just the tip of the iceberg, since the estimated number of victims that are recruited and sexually exploited yearly in the Netherlands, amounts to approximately 3000 young women, of whom roughly 1300 are minors. Of these estimated 1300 minors, only 29 victims were detected in 2018. Thus, around 


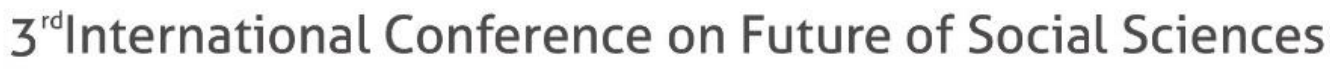

97-98\% remained invisible to the authorities (youth care and police), and the traffickers could not be prosecuted (Dutch Rapporteur, 2019b).

Sex trafficking is defined as "The recruitment, transportation, transfer, harboring or receipt of persons by means of threat or use of force or other forms of coercion, of abduction, of fraud, of deception, of the abuse of power or of a position of vulnerability or the giving or receiving of payments or benefits to achieve the consent of a person having control over another person" (UN Palermo Protocol, 2000). Kragten-Heerdink, Detteijer-Vermeulen and Korf (2017) distinguished two (main) forms of sex trafficking, namely domestic and crossborder sex trafficking. Domestic sex trafficking is where recruitment and exploitation take place in one country, while cross-border sex trafficking (arrived, departed and traversed) is the situation in which recruitment and exploitation take place in (at least) two different countries. In the Netherlands, almost half of the known victims of sex trafficking were victims of domestic sex trafficking (Dutch Rapporteur, 2020).

An extensive number of studies have been conducted on victims or recruitment tactics of (domestic) sex trafficking, whereas studies that have focused on the background and networks of sex traffickers have remained scarce. However, knowledge of sex traffickers and their networks is crucial to develop specialist interventions that prevent them from (re)offending (Drummond \& Southgate, 2018) and that help detection and persecution of sex traffickers. Furthermore, it is useful to be able to detect and protect victims. Therefore, this study aimed to provide a detailed description of male traffickers of domestic sex trafficking. In recent years, more studies have shifted their attention from victims to sex traffickers. However, studies that have been conducted on sex traffickers generally made no clear distinction between the type of trafficking and the gender of the traffickers. When comparing domestic and cross-border traffickers and comparing male versus female traffickers, several distinctions appeared related to the background of the traffickers, the way they operate and the networks they operate in.

\subsection{Cross-border sex trafficking versus domestic sex trafficking}

Based on earlier studies, three main differences in background characteristics, modus operandi and networks could be identified between cross-border and domestic sex traffickers.

First, the Dutch Rapporteur demonstrated that traffickers of domestic sex trafficking were younger and mainly born in the Netherlands compared to traffickers of cross-border sex trafficking (Dutch Rapporteur, 2019a). In the Netherlands, cross-border sex traffickers were aged on average 33 years, compared to 27 years for domestic sex traffickers (Dutch Rapporteur, 2019a). Also, two out of three persecuted sex traffickers of domestic sex trafficking (67\%) were born in the Netherlands, compared to $18 \%$ of the traffickers of crossborder sex trafficking, who were mostly born in Eastern Europe (Dutch Rapporteur, 2019a).

Second, an apparent difference related to the used recruitment tactics was made clear. Surtees (2008) suggested that cross-border traffickers possibly use less violence against their victims compared to domestic sex traffickers. She described that instead they might make more use of the vulnerable position of the victims (for example poor living conditions, already working in prostitution in their country of origin in bad conditions) or they tend to make use of false promises (for example doing legal work in the country of destination, promise of marriage) to recruit victims. Once in the country of destination, traffickers of cross-border trafficking might also rely more on the cooperation of the victim or their dependency on the trafficker(s), instead of using force. This conclusion is supported by 


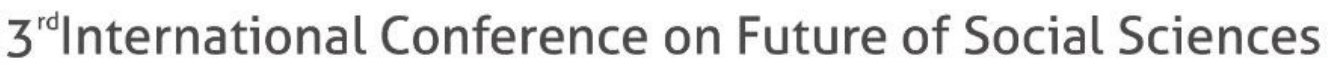 \\ 5 - 7 March 2021 \\ BERLIN, GERMANY}

findings of the Dutch Rapporteur, who demonstrated that domestic sex trafficking was more often accompanied by violence, compared to cross-border trafficking (Dutch Rapporteur, 2019a).

And third, networks of domestic sex traffickers were generally found to be smaller and less organized compared to networks of cross-border sex trafficking (Dutch Rapporteur, 2012; Boerman, Grapendaal, Nieuwenhuis and Stoffers, 2017). Shively, Smith, Jalbert and Drucker (2017) also implied that most convicted traffickers (of which a majority had no international component) operated either alone or conspired with just one to three other individuals whom they mostly know through social or family ties. On the other hand, it is suggested that cross-border sex traffickers generally operated in well-organized criminal networks because it requires more organization to recruit, transport, house and employ victims, and these criminal networks usually co-operate with locally organized networks (Van Rij \& McAlister, 2019). However, Surtees (2008) stated that cross-border sex traffickers in South-Eastern Europe are generally comprised of well-organized criminal networks, but individuals acting alone or small local criminal groups were also present. Also, while the well-organized criminal networks have dominated in the past, the trend seemed to be shifting towards more flexible, hybrid, small-scale networks, mostly operating from Eastern Europe or Africa (Van Rij \& McAlister, 2019). Constantinou (2019) for example found that sex traffickers on Cyprus (of which the majority recruited victims from foreign countries) that co-operated (55\%), were mostly part of small-scale criminal groups.

Despite these differences, most studies included both traffickers of cross-border and domestic sex trafficking or only traffickers or cross-border sex trafficking. It is because of this that this study could offer new insights as it includes only traffickers of domestic sex trafficking.

\subsection{Male versus female sex traffickers}

Differences were also found in the background and role of male versus female traffickers. Previous studies found that the vast majority of sex traffickers is male. In the period 20132017, a staggering $84 \%$ of the offenders that were convicted in the Netherlands for sex trafficking were male (Dutch Rapporteur, 2019a). In other studies, the (estimated) proportion of the female sex traffickers varied from 4\% (Hargreaves-Cormany, Patterson and Muirhead, 2016) to $25 \%$ (Roe-Sepowitz, 2019).

Not only does the prevalence of male and female traffickers differ, but also their role (Roe-Sepowitz, Gallagher, Risinger and Hickle, 2019; Roe-Sepowitz, 2019; Surtees, 2008; Wijkman and Kleemans, 2019) and the dynamic of inauguration into sex trafficking (MiccioFonseca, 2017) appears to be different. For example, Surtees (2008), Constantinu (2019) and Miccio-Fonseca (2017) described that females were often responsible for recruitment of victims or they were victims themselves and they were being used by their trafficker to recruit new victims, probably as they are considered more trustworthy by girls and women. Female traffickers mostly are former victims of sexual exploitation, who are forced into enlisting new victims as opposed to their male counterparts (Miccio-Fonsesca, 2017).

Also, female sex traffickers were less likely to operate on their own (Constantinu, 2019; Wijkman and Kleemans, 2019; Roe-Sepowitz, 2019). Wijkman and Kleemans (2019) for example demonstrated that $95 \%$ of the convicted women were part of a network in which they operated and in almost $75 \%$ of these cases, the man they cooperated with was their partner. This highlights the need to take gender into account when studying sex traffickers. 


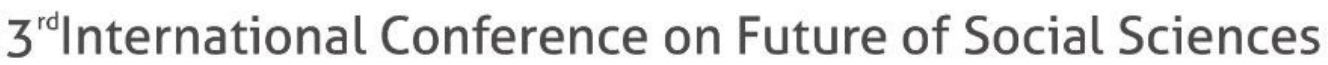

\subsection{Current study}

Considering the differences between domestic and cross-border sex trafficking and male and female traffickers, the goal of the study is to describe specific and distinguishable characteristics of male domestic sex traffickers and their networks.

This multi-case study focused on male offenders of sex trafficking of female minors and adolescent victims (up to 23 years). The main reason to include only traffickers of female victims up to 23 years is that most (known) victims in the Netherlands are female $(98 \%$ according to the Dutch Rapporteur, 2019b) and the majority is either a minor (30\%) or an adolescent (35\%) (Dutch Rapporteur, 2019b). The choice was made to include victims up to the age of 23 years, since the developmental phase of biological maturation is considered to end around the age of 23 years.

A description of the background of sex traffickers and the networks they operate in is provided by analyzing 25 police files of convicted sex traffickers. Based upon the background of the traffickers, the following categories were distinguished: (i) demographics (age, country of origin, family status), (ii) socioeconomic status (income, educational level, debts), (iii) psychosocial background (biographic anamneses, alcohol and drug (ab)use, personal characteristics) and (iv) criminal carrier. When traffickers operated in networks for domestic sex trafficking, (v) size, (vi) structure and (vii) composition of the networks are described. In the discussion, the findings of the current study were compared to previous known studies, aimed at describing a profile of the sex traffickers and their networks.

\section{Methodology}

This study is set out as a multi-case study. It aimed at gaining insight into characteristics and information on networks of male (domestic) sex traffickers. Data was obtained from police and court files of convicted sex traffickers in the Netherlands. The police and court files provided a comprehensive set of information about the sex traffickers, from the vantage point of individuals involved in the trafficking. As traffickers have proven to be an unreliable source of information (Shively et al., 2017; Copley, 2013; Van San and Bovenkerk, 2013; Mehlman-Orozco, 2020), this study utilized multiple data sources which provided different perspectives on the position of the trafficker (i.e. from data carriers, victims, police officers, judges and forensic psychologists). By using these multiple sources of information and reports, an in-depth understanding could be made of sex traffickers (Cresswell, 2007).

In order to gain access to the police files, written permission of the Board of ProcuratorsGeneral was obtained and support was given by both the police and the prosecutions' office.

\subsection{Data selection}

Selection of cases for the study, was based upon the following inclusion criteria: (i) Gender (male), (ii) a conviction for sex trafficking between 2016 and 2019, (iii) Domestic sex trafficking (grooming and exploitation took place in the Netherlands) and (iv) at least one of 


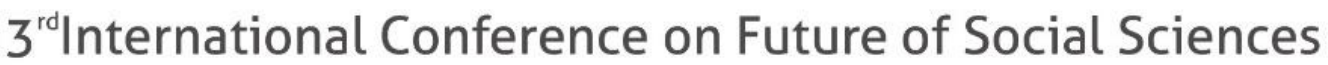 \\ 5 - 7 March 2021 \\ BERLIN, GERMANY}

the victims of whom exploitation was proven in court, was under 24 years of age at the start of the exploitation.

In the Netherlands, no national registration system existed that could be consulted to select cases meeting these inclusion criteria. Therefore, the ten regional sections of the Immigration police department, responsible for investigating human trafficking (AVIM's) were approached and asked how many cases they had which met the inclusion criteria, if any. In total, 55 cases were identified, divided over eight AVIM's. Next, a stratified sampling method (Patton, 1990) was applied to gain coverage of cases in all regions in the Netherlands. When more cases were available in one region, the cases were selected on the basis of the date of the conviction in which the most recent convictions were included in the study (according to the method of systematic sampling). By applying this method of sampling, the researchers had the least influence on the selected cases and by doing so increasing the credibility of the data. Out of seven of the eight AVIM's at least two cases were included, with a maximum of six (of one AVIM, no cases were included). The cases were selected and analyzed between October 2018 until May 2019. In total, 25 cases were selected that met all the inclusion criteria. The use of these 25 cases was supported by and based upon the use of saturation as a criterion for validation.

\subsection{Sample}

In the 25 cases, a total of 39 traffickers were convicted for sex trafficking. In most cases, only one trafficker was convicted $(n=19)$. The maximum of traffickers that were convicted in one case is five $(n=1)$. In these 25 cases, sexual exploitation was proven for 39 victims. At the same time in most cases sex trafficking was proven for one single victim $(n=16)$. The maximum of victims in a single case was five $(n=1)$.

In cases in which more than one trafficker was convicted, one trafficker was selected for the study. This was the trafficker who received the highest sentence. The rationale behind this was threefold: First, it was expected that the trafficker who received the highest penalty played the most important role in the exploitation of the victim. Second, it was expected that most information would be available for the trafficker that received the highest penalty. Third, by only selecting one trafficker in each case, it was possible to include more unique situations covering more cases. This way, more data could be obtained regarding distinct networks of traffickers.

\subsection{Data collection}

Data collection consisted of extensively reading and analyzing the cases one by one (within-case analysis). All the information sources that were present in the files were considered useful for the current study. The used sources of information could be categorized into five categories: (i) official acts from authorities (including f.e. transcripts of wiretaps), (ii) verdicts of judges, (iii) reports of probation officers and reports of forensic psychologists (called pro Justitia reports) (iv) statements and in depth testimonies of victims and witnesses and (v) statements of the traffickers themselves. Since each data source has its limitations, they were ranked on their expected reliability. The source expected to be most reliable was mentioned first, and the source expected to be least reliable was mentioned last. For example, 


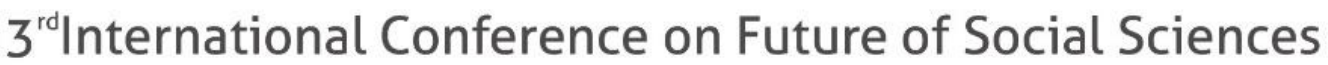 \\ 5 - 7 March 2021 \\ BERLIN, GERMANY}

although official acts could be considered a reliable source, they mostly provide little indepth insight into experiences or backgrounds of victims and/or traffickers. Also, it was possible that information retrieved from the aforementioned sources could contradict each other. Most obviously, the statements of traffickers could contradict with testimonies from victims. For the purpose of gaining reliable information, data and method triangulation was applied (Denzin, 2015). Information from the distinguished sources was combined to be able to shape a complete image of the traffickers. When information was contradictory, data was selected based on the reliability of the source. Combining these sources provided a complete portrayal of a trafficking situation.

\subsection{Data analysis}

To analyze the data, a framework analysis was applied. Framework analysis is a systematic and structured method that allows for producing descriptive and/or explanatory conclusions about themes in large datasets (Gale et al., 2013). Several stages were traversed in the analytical process (Gale et al., 2013). First, the researchers familiarized themselves with the data. After this, a first draft of an analytical framework was constructed, consisting of pre-determined categories based on literature. For each category, a categorization was made beforehand, making a quantifiable description possible. The framework contained a detailed description of the categories that were the subject of the study. Relevant data was written out or summarized, allowing for qualitative analysis later on.

When a first analytical framework was constructed, it was applied on six cases to test the framework. After analyzing the first six cases, the researchers evaluated the framework and reflected on the categories. A working analytical framework was constructed and applied in subsequent cases.

After the coding of ten cases, a validation check was conducted. A preliminary analysis was conducted and presented to different experts in the field, who were not involved in the data collection. After reflecting on the preliminary analysis, the analytical framework was tightened, based upon questions that were raised during the reflection. After this, the last fifteen cases were analyzed. At the end of the data collection period, missing data of the first ten cases due to adjustments of the framework were retained from the files. The advantage of accommodating both a priori and emergent issues is that the framework is focused around research questions, but it also provided flexibility to discover (more specific) sensitizing concepts that could encouraged further reading in the next cases.

After having read the 25 cases, a thematic analysis across the cases was carried out (cross-case analysis). The data of each category was charted, which meant the data was summarized and the themes were described in more depth.

\section{Results}

As outlined in the introduction, the main purpose of this study was to gain insight into the background characteristics and networks of sex traffickers. In this section, the information that was obtained from the files of convicted traffickers is explained. 


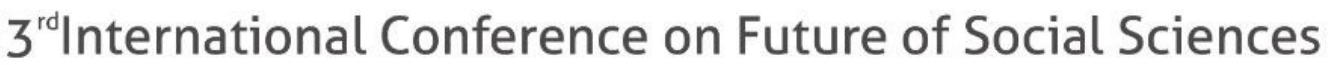 \\ 5 - 7 March 2021 \\ BERLIN, GERMANY}

\subsection{Background of sex traffickers}

In this section, the results related to the background of the sex traffickers are outlined. First, the demographics of the sex traffickers are described, followed by the socioeconomic background and the psychosocial background. Finally, the criminal carrier of the sex traffickers is presented.

\subsubsection{Demographics}

The demographics are divided into four separable variables: (i) age, (ii) migration background, (iii) relational status and contact with parents, and lastly (iv) contact with children.

The age of the sex traffickers was established at the beginning of the exploitation period of their victim (table 1). In the cases with multiple victims, the age of the traffickers at the beginning of the exploitation of their first victim was established. The average age of the studied sex traffickers was 26,4 years. Of the sex traffickers $72 \%$ were between 18 and 29 years old. Only one of the studied sex traffickers proved to be a minor at the beginning of the exploitation period. The maximum age of the traffickers was 43 years. The average age of the victims on the other hand was 18,3 years at the beginning of the exploitation phase, which made the age difference between the traffickers and their victims slightly over eight years.

Table 1. Age of the trafficker at the beginning of the exploitation phase $(n=25)$

\begin{tabular}{lcc}
\hline \multirow{2}{*}{ Variable } & Frequency & (Valid) percentage \\
\cline { 2 - 3 } Age & $(\mathbf{n})$ & $(\%)$ \\
18- years & 1 & $4 \%$ \\
18-23 years & 9 & $36 \%$ \\
24-29 years & 9 & $36 \%$ \\
30+ years & 6 & $24 \%$ \\
\hline
\end{tabular}

Due to privacy regulations, the ethnicity of both the traffickers and victims is not registered in the files. The migration background had to be deduced based on the (susceptible) country of origin of the parents of the subjects involved. The data outlined that, although most traffickers hold Dutch nationality (72\%) and were born in the Netherlands $(64 \%)$, the majority $(83 \%)$ had parents that originated in a foreign country (table 2 ).

Table 2. Nationality, country of origin and migration background of the traffickers $(n=25)$

\begin{tabular}{lccc}
\hline \multirow{2}{*}{ Variables } & Frequency & (Valid) percentage \\
\cline { 3 - 4 } & & $(\mathbf{n})$ & $(\%)$ \\
\hline \multirow{2}{*}{ Nationality } & & \\
& Dutch & 18 & $72 \%$
\end{tabular}




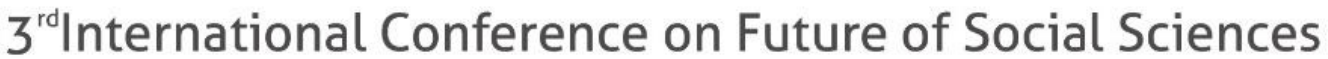

\section{5 - 7 March 2021}

4

3

Double nationality

\section{Country of origin}

\author{
Netherlands \\ Other country

\section{Migration} \\ background
}

BERLIN, GERMANY

\begin{tabular}{ccc} 
The Netherland & 4 & $16 \%$ \\
Other country & 21 & $84 \%$ \\
\hline notes: Double nationality is the Dutch nationality combined with another nationality
\end{tabular}

Third, the results outlined that most traffickers were in a relationship during the exploitation phase (table 3). Out of the nineteen traffickers that were in a relationship, in seven cases this was with the victim (37\%), nine with someone other than the victim (47\%) and three $(16 \%)$ were in a relationship with both the victim and another person during the time the exploitation took place. Out of three of the twelve cases where the trafficker was involved in a relationship with someone else than the victim, their partner had knowledge of the exploitation and even played a part in it. The other six traffickers were single during the exploitation (24\%). It is noteworthy that five of these six traffickers had sex with the victim.

Related to the contact with their parents, the results implied that half of the traffickers had contact with both parents (52\%). Although the quality of the contacts with their parents could not always be extracted from the files, in some cases it appeared that contact with (at least) one of their parents was sporadic. In five cases for example, the father of the trafficker lived in a foreign country and the traffickers barely saw them. Of two other traffickers it could be deduced that they had contact with their father, but the quality of their relationship was superficial. Nine other traffickers (36\%) only had contact with one of their parents, mostly with their mother (eight of the nine traffickers). In the majority of these nine cases, the father abandoned the family (mostly when the traffickers were under the age of four), or they never had contact with their father. The last three traffickers had no contact with either of their parents $(12 \%)$.

Table 3. Relational status and contact with their parents $(\mathrm{n}=25)$

\begin{tabular}{ccc}
\hline \multirow{2}{*}{ Variables } & Frequency & (Valid) percentage \\
\cline { 2 - 3 } & $(\mathrm{n})$ & $(\%)$ \\
\hline
\end{tabular}

\section{Relational status}

\section{Single}

In relationship
$24 \%$

$76 \%$ 


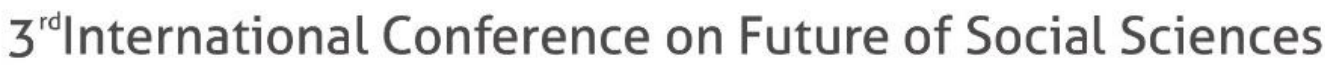

Contact with parents

\begin{tabular}{|c|c|c|}
\hline $\begin{array}{r}\text { Contact with both } \\
\text { parents }\end{array}$ & 13 & $52 \%$ \\
\hline $\begin{array}{r}\text { Contact with one } \\
\text { parent }\end{array}$ & 9 & $36 \%$ \\
\hline $\begin{array}{r}\text { No contact with } \\
\text { parents }\end{array}$ & 3 & $12 \%$ \\
\hline
\end{tabular}

Finally, it appeared that almost two thirds of the researched traffickers have children (table 4). Of the traffickers who have children, most were still in contact with them (87\%). Although the quality of the contact with their children could not be determined objectively from the files, most traffickers mentioned they were in good contact with their children. The mother of the children was in most cases an ex-partner (80\%). Two traffickers had children with one of their victim(s) and one trafficker had children with his current partner. The average age of the traffickers with children was with 29,8 years, which is higher when compared to the age of traffickers without children, which was 21,8 years.

Table 4. Children $(\mathrm{n}=25)$

\begin{tabular}{rcc}
\hline \multirow{2}{*}{ Variable } & Frequency & (Valid) percentage \\
\cline { 2 - 3 } & $(\mathbf{n})$ & $(\%)$ \\
\hline Children & & \\
Yes & 15 & $62 \%$ \\
No & 9 & $38 \%$ \\
Unknown & 1 & - \\
\hline
\end{tabular}

\subsubsection{Socioeconomic background}

To establish the socioeconomic status, this category is divided into three variables: (i) the employment status, (ii) education level and (iii) the debts of the traffickers. First, the results indicated that, during the exploitation phase, slightly more than half of the traffickers were employed (52\%). However, it appeared that their income was unstable and too low to be selfsufficient. The traffickers for example worked under a flexible hourly contract, they had low payed jobs or they worked part-time. Their employment could be linked to their education level. Most traffickers, namely fourteen (67\%), had no degree (they left high school and/or never finished a study). Only seven traffickers (33\%) had a degree of further education BTEC level (called 'MBO' in the Netherlands). Several explanations for the finding that most traffickers had no degree, could be obtained from the files. They were, for example, taken into custody during their studies, they had to leave their school due to placement in residential care facilities as a minor, they stopped because of a lack of motivation, or they were expelled from school due to behavioural problems. 


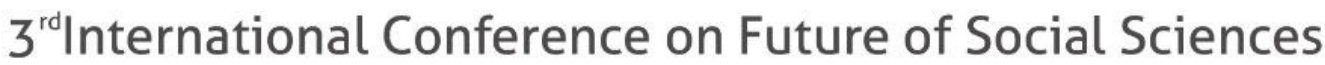 \\ 5 - 7 March 2021 \\ BERLIN, GERMANY}

Last, the results showed that three quarters of the traffickers had debts (table 5). From eleven of the sixteen traffickers with debts, it was possible to gain insight into the amount of their debt. Slightly more than half of these eleven traffickers $(55 \%)$ had a debt of between 5.000 and 10.000 euros. Three traffickers had debts that exceeded 10.000 euros, up to several tens of thousands of euros. The results pointed to the likelihood that their debts were mostly due to a reclamation of incorrectly calculated taxes or social benefits which had been received, a recovery of criminal earnings by the state, or not being able to pay their bills, for example due to their low income or losing their job.

Table 5. Employment status, educational level and debts $(\mathrm{n}=25)$

Variables

Frequency (Valid) percentage

(n)

$(\%)$

Employment status

$\begin{array}{rcc}\text { Employed } & 12 & 52 \% \\ \text { Not employed } & 11 & 48 \% \\ \text { Unknown } & 2 & -\end{array}$

Educational level

$\begin{array}{rcc}\text { Highly educated } & 0 & 0 \% \\ \text { Medium educated } & 7 & 33 \% \\ \text { No education } & 14 & 67 \% \\ \text { Unknown } & 4 & -\end{array}$

Debts

$\begin{array}{ccc}\text { Yes } & 16 & 76 \% \\ \text { No } & 5 & 24 \% \\ \text { own } & 4 & -\end{array}$

\subsubsection{Psychosocial background}

A third category that is described is the psychosocial background of the traffickers. The variables that are described are (i) the childhood of the traffickers and (ii) alcohol- and/or drugs (ab)use (table 6). Also, based on forensic psychiatrists' reports, a description of the characteristics is given.

Firstly, the childhood of the traffickers was categorized into three categories, ranging from a highly traumatic childhood to low-level traumatic childhood. It is identified that thirteen traffickers had a highly traumatic childhood $(32 \%)$ or a moderately traumatic childhood $(27 \%)$. A highly traumatic childhood was operationalized as traffickers having experienced several adverse childhood experiences at an age younger than six years. These traffickers 


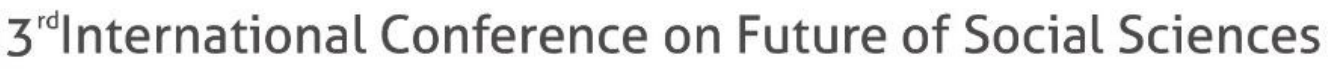 \\ 5 - 7 March 2021 \\ BERLIN, GERMANY}

experienced, for example, violence induced by their parents, neglect (emotional and/or physical), a war in their country of origin, or placements in foster care or residential care facilities due to their problematic home situation. A moderately traumatic childhood was operationalized as having faced several (potentially) traumatic events from the age of six onwards. Examples were being abandoned by their father, being placed in a residential care facility during puberty, suicide of a friend, or death of a close family member. Nine traffickers $(41 \%)$ were categorized into the third category, which meant that they had a lowlevel traumatic childhood. In these cases there was no information or no signals were present that the traffickers had experienced any (potentially) traumatic events during their childhood. Nevertheless, the files implied that few traffickers had a childhood free of problems. As described earlier, most traffickers had, for example, an unstable home situation or lacked ample contact with (one of their) parents.

Second, alcohol- and drug (ab)use of the traffickers was also categorized into three categories ranging from highly problematic alcohol and/or drug (ab)use to low-level problematic alcohol and/or drug (ab)use. Based on the information in the files, seven traffickers were labeled as having highly problematic alcohol and/or drug use (30\%). That meant, these traffickers used regularly, (almost) daily, (hard) drugs from puberty onwards and/or were currently addicted. Seven traffickers were labeled as having medium problems with alcohol and/or drug use (30\%). These traffickers had a history of addiction (no signals appeared that they were addicted during the exploitation period), used to use hard drugs in the past, or used (soft) drugs and/or alcohol (a few times a week). For nine traffickers, no signals were present in the files they had (had) problems with alcohol and/or drug use (39\%). They mentioned they did not currently use or used drugs recreationally (mostly once or twice a month), and no signals in the files pointed in other directions.

Table 6. Childhood and alcohol- and/or drug use of the traffickers $(n=25)$

\begin{tabular}{rcc}
\multirow{2}{*}{ Variables } & Frequency & (Valid) percentage \\
\cline { 2 - 3 } Childhood & $(\mathbf{n})$ & $(\%)$ \\
Highly traumatic childhood & 7 & $32 \%$ \\
Moderately traumatic childhood & 6 & $27 \%$ \\
Low traumatic childhood & 9 & $41 \%$ \\
Unknown & 3 & - \\
Alcohol and drug (ab)use & & \\
Highly problematic & 7 & $30 \%$ \\
Medium problematic & 7 & $30 \%$ \\
Not problematic & 9 & $39 \%$ \\
Unknown & 2 & - \\
\hline
\end{tabular}




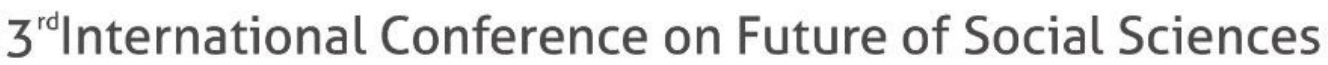 \\ 5 - 7 March 2021 \\ BERLIN, GERMANY}

In twelve cases a forensic psychologist was asked to advise the court on whether or not the traffickers could be held responsible for their actions. Based on these reports, a detailed description could be provided into the personality of the traffickers. These reports concluded that the traffickers had personality problems. The forensic psychologists uncovered several personality disorders and, according to the forensic psychologists, the traffickers showed in general narcissistic, antisocial or borderline traits. According to the forensic psychologists, the traffickers showed a lack of remorse towards their victims, or placed their own needs above that of their victims.

\subsubsection{Criminal carrier}

As can be seen in table 7 , four traffickers were first offenders, which meant they have never been convicted of a criminal offence (16\%). The traffickers with a criminal record were categorized as having a medium criminal record or a high criminal record. The criminal record of six traffickers could be labeled as a medium criminal record (24\%). The traffickers in this category committed (several) criminal offences that could be considered relatively light. They were convicted with a fine (no prison sentence) or the offences were not accompanied by violence against others. Examples of criminal offences in this category were fraud, property offences and traffic violations. Most traffickers, however, were labeled as having a high criminal record $(60 \%)$. These traffickers committed numerous offences that could be labeled as serious, and were mostly accompanied by violence. They were all convicted (sometimes even numerous times) with a prison sentence. These offences included attempted murder, extortion (accompanied with violence), street robbery, drug offences and/or trade in weapons and ammunition. Mostly the first offence was committed as a minor.

Table 7. Criminal record of the trafficker $(n=25)$

\begin{tabular}{lcc}
\hline \multirow{2}{*}{ Variable } & Frequency & (Valid) percentage \\
\cline { 2 - 3 } Criminal record & $(\mathbf{n})$ & $(\%)$ \\
High criminal record & 15 & \\
Moderately criminal record & 6 & $60 \%$ \\
No criminal record & 4 & $24 \%$ \\
\end{tabular}

Two out of the twenty-five traffickers were recidivists. That meant that two traffickers had an earlier conviction for sex trafficking. One trafficker was convicted fifteen years earlier and the other trafficker was convicted four years earlier. Next to these two traffickers, two other traffickers did not have an earlier conviction for sex trafficking, however, they had been recorded in the police system for involvement in non-licensed (illegal) prostitution. Finally, three traffickers had a past conviction or were suspected of (paedophiliac) sexual offences, for example sexual abuse, fornication or child pornography.

\subsection{Networks}




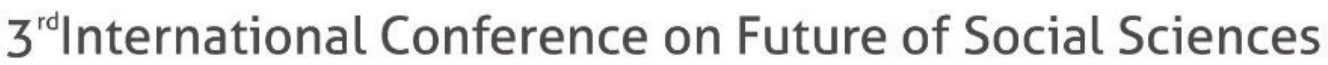 \\ 5 - 7 March 2021 \\ BERLIN, GERMANY}

In this paragraph, the networks of the traffickers are studied more in-depth. In 15 of the 25 studied cases, it appeared that the traffickers operated in a network. In these cases multiple traffickers were convicted or charged for sex trafficking, or it could be deduced from the files that more than one trafficker was involved in the exploitation. This section only contains the data of these 15 files.

\subsubsection{Size}

Out of six of the fifteen cases in which traffickers operated in networks, more than one trafficker was convicted for sex trafficking. In total fourteen other traffickers were convicted in these six cases (with a maximum of five traffickers in one case). Ten of the fourteen traffickers were male and four of them were female. The female traffickers were the partners of (one of) the male traffickers during the exploitation. The average age of the six traffickers that were part of this study (26,2 years), was slightly higher compared to the mean age of the other traffickers in their networks (25,8 years; ranging from 17 to 56 years).

In the other nine cases, only one trafficker was convicted. From the files, however, it could be identified that they had operated in a network. In these files, other suspects were mentioned and investigated but were not convicted due to a lack of evidence. Also, the victims and/or witnesses mentioned the involvement of others who could not be traced by the police, or their involvement was not sufficient enough for them to be considered to be a suspect. Despite the fact that they were not officially a suspect or convicted, in this study they were considered as part of the network. These networks also comprised a maximum of five persons.

\subsubsection{Structure}

The way the networks operated and how they were organized is elaborated herein. First, it was analyzed who (the trafficker himself or another trafficker) was responsible for the initial contact with the victim, the grooming, the exploitation, housing and transport of the victims. Based on the files two different structures could be divided: (i) a facilitative cooperation and/or (ii) an organized cooperation.

In a facilitative cooperation $(n=8)$, only the trafficker was responsible for the exploitation of the victim(s). The trafficker was also primarily responsible for all other tasks, however these tasks were incidentally taken over by other traffickers. The tasks were mainly assigned to others when the trafficker had little time (for example in the cases with multiple victims) or when he was incarcerated. Also, in some cases other traffickers only initiated contact with the victim and introduced her to the trafficker.

In an organized cooperation $(n=7)$, the traffickers fully operated in cooperation during the exploitation of the victim. Based on the results, it would seem that the traffickers collaborated during the exploitation to divide the tasks or consulted about the tactics for the exploitation (where to work, how to get customers, the price etc.).

In most of the fifteen networks, the structure seemed to be based on equality $(n=12)$, as opposed to being merely hierarchical $(n=3)$. In the three cases with a mere hierarchical structure, the trafficker seemed to make all decisions without consulting fellow traffickers or they employed violence to enforce their decisions. In all three cases there seemed to be a situation of facilitative cooperation. In the other twelve cases, the cooperation was based on 


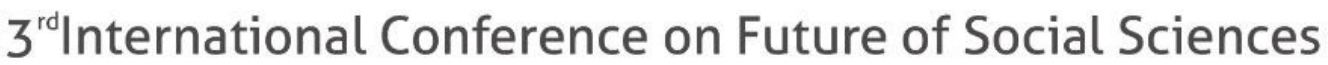 \\ 5 - 7 March 2021 \\ BERLIN, GERMANY}

equality with mutual respect amongst the traffickers. In these cases no signals that one of the traffickers was placed (or placed himself) above the others were present.

\subsubsection{Composition}

The composition of the networks was based upon the (susceptible) country of birth of their parents but next to this the social composition of the groups were analyzed.

Based on the information in the files, in most networks the (susceptible) country of birth of the parents of the traffickers appeared to be predominantly homogenous $(n=7)$. That meant that the parents of most, but not all of the traffickers in the networks shared a country of origin. In three cases, the parents of all the traffickers shared the same country of birth $(n=3)$. Last, in five cases the groups seemed to be heterogenous $(n=5)$. The results illustrated that none of the networks were comprised of traffickers with solely familial ties. That means that in all 15 studied networks, social (informal) ties were present. In five of these cases, a combination of social (informal) ties and familial ties appeared $(n=5)$. In these networks, mostly a cousin or a brother of the main trafficker was part of the network.

When looking closer into the ties between the members of the networks, it would be reasonable to assume that these ties were mostly weak and superficial $(n=12)$. The traffickers described their fellow traffickers as acquaintances whom they knew only for a short period of time and/or superficially. These ties merely existed during and because of the exploitation. The results implied that before the exploitation phase, they had a quarrel, knew each other superficially from the street or had only seen each other a few times via a common friend. In three networks, the girlfriend of the traffickers was part of the network. The files however showed that the contact between the trafficker and his girlfriend was broken during the trial $(n=3)$. In only three networks did the traffickers point out that (one of) their fellow trafficker(s) was a close friend or their best friend $(n=3)$.

\subsubsection{Other criminal activities}

In eight of the 15 networks, the results revealed that the traffickers were involved in other criminal activities, apart from sex trafficking. Victims and witnesses stated that the traffickers were mostly involved in drug trafficking or other drug related crimes. Other common criminal activities among the traffickers seemed to be weapon trafficking, fraud, money laundering and scams.

\section{Discussion}

Prior work has given some insight into sex traffickers and the networks they operate in. However, most previous studies made no distinction between traffickers of distinctive forms of trafficking and the gender of the traffickers; they often included both cross-border and domestic sex traffickers as well as male and female traffickers. This study provided a profile of male sex traffickers who engaged in domestic sex trafficking, by analyzing police and court files. In the discussion, first, the findings of the current study are compared to findings of previous studies. The purpose is to gain an overview of the current knowledge about domestic sex traffickers and their networks, and to review where the results of this study contradict or complement earlier findings. Knowledge gaps or differences in findings could 


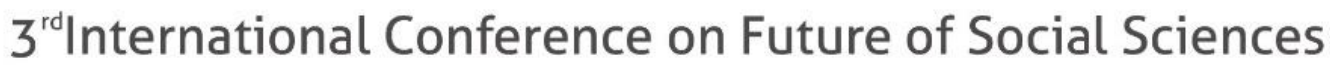

be incentives to further research. It should, however, be noted that these comparisons should be interpreted with caution. Due to differences in, for example, operationalization, study method or sample and a gap in research on the topic, a one-on-one comparison is not always possible or legitimate. Next, based on the results, a profile of male domestic sex traffickers and their networks is provided.

\subsection{Background of traffickers}

First, the results of this study concerning the demographics of the sex traffickers were in general similar with earlier studies. An earlier study in the Netherlands (Dutch Rapporteur, $2019 \mathrm{a} ; 2020$ ) found a mean age of 27 years. In the United states, the mean age of traffickers in two studies was 25,1 years (Reid, 2016) and 28,5 years (Roe-Sepowitz, 2019). The mean age of the traffickers in this study was 26,4 years. Minors in all studies were mere exceptions. According to Van Dijke, de Ruiter and Terpstra (2015) most traffickers start from an age of 20 years, because minors mostly lack the skills needed to groom and exploit victims and the organization of an exploitative situation. Although most traffickers in this study were born in the Netherlands and hold Dutch nationality, the majority seemed to have a migration background. This finding is consistent with findings of studies from the Netherlands (Van Dijke et al., 2015) and the United States. The studies from the United States found that most of the sex traffickers were African American: ranging from 72\% (Roe-Sepowitz, 2019) to 91\% (Hargreaves-Cormany et al. 2016). Compatible with earlier findings of Rijken, Muraszkiewicz and van der Ven (2015), most of the traffickers studied seemed to be in a relationship, of which almost half had a relationship with the victim and slightly more than half with a person other than the victim. Although most of the traffickers studied had contact with both of their parents, a substantial number of the traffickers in this study on the other hand had no contact with their father. This was also compatible with earlier findings of Rijken et al. (2015), who found that around two-thirds of the traffickers in the Netherlands were raised in disrupted families. Similar to the results of the current study, a substantial part of the traffickers had a bad relationship with their father. Findings of a previous study concerning whether traffickers had children were contradictory to the findings of this study. Rijken et al. (2015) showed that all the traffickers studied in the Netherlands had children, while in this study slightly more than half of the traffickers had children.

Second, the results of this study indicated that the traffickers in this study had a low socioeconomic status. Almost half of the traffickers were employed; however, their income seemed to be low and flexible. Also, most traffickers had no education and had debts. These findings seemed compatible with earlier studies (Van Dijke et al. 2015; Dutch Rapporteur, 2014; Van San and Bovenkerk, 2013; Rijken et al., 2015), however, the percentage of (suspected) traffickers who were employed in this study were higher compared to an earlier study of the Dutch Rapporteur (2014). In the study of Van Dijke et al. (2015) nine of the fourteen interviewed traffickers did not finish their education. According to them, this could be counted as an important instigator to commit criminal acts.

Third, more than half of the studied traffickers seemed to have experienced a highly to moderately traumatic childhood and were categorized as having high to medium problematic alcohol and drug use. These traumatic experiences were violence induced by their parents, neglect (emotional and/or physical), experiencing a war in their country of origin or experiencing placements in foster care or residential care facilities (highly traumatic experiences), being abandoned by their father, being placed in a residential care facility in 


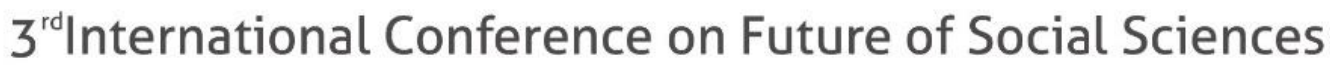

puberty, suicide of a friend or death of a close family member (moderately traumatic experiences). This seemed compatible with the findings of Van Dijke et al. (2015) and Hackett and Smith (2018) who found that negative childhood experiences were found in most cases of perpetrators of child sexual exploitation. The traffickers in this study were (in general) described by forensic psychologists as narcissistic, antisocial or having borderline traits. According to the forensic psychologists, the traffickers showed a lack of remorse towards their victims, or placed their own needs above that of their victims. This seemed compatible with previous studies, which had established a link between sex traffickers and psychopathic traits. Compared to the general prison population for example, sex traffickers showed more psychopathic traits, mainly interpersonal and affective traits. That meant that sex traffickers showed more superficial charm, grandiose sense of self-worth and were more manipulative (interpersonal) and showed more lack of remorse, shallow affect, lack of empathy and failure to accept responsibility for their actions (Reid and Fox, 2019). Most offenders who met the criteria for psychopathy were classified as violent charismatic/manipulative (Hargreaves-Cormany et al., 2016). Van Dijke et al. (2015) stated that these psychopathic characteristics are needed to exercise this instrumental form of violence. They described that to deliberately exploit a young girl, someone has to cross a boundary. A trafficker needs to have a certain amount of ruthlessness and to depersonalize the victim to be able to do this and continue with it.

Fourth, a very high proportion of the traffickers studied had a long criminal record, with a diversity of offences that could be labeled as serious or that were accompanied by violence. This seemed consistent with an earlier study of Rijken et al. (2015) who found that most of the sex traffickers in their study (87\%) were convicted earlier, merely for violent crimes, property crimes, theft or traffic-related crimes. The findings were also consistent with studies in the United States, that found 96\% (Shively et al., 2017) and 97\% (Heargreaves-Cormany et al., 2016) of the traffickers had a criminal record. On the other hand, Roe-Sepowitz (2019) showed that only $24 \%$ of the traffickers had a criminal record, mainly for violence against other people (33\%), property crimes (29\%) and drug possession (28\%). Van Dijke et al. (2015) mentioned that the criminal acts of traffickers were increasing in seriousness as they became older. Most of the traffickers start with small criminal acts and 'grow' into sex trafficking. In this study, there were no signals of the presence of such a 'criminal ladder'. In line with the findings of Hackett and Smith (2018), the sex traffickers could be characterized as generalists, rather than specialists, since most of the studied traffickers had committed a wide range of non-sexual offences. Also, the results point out that the majority of the traffickers could be considered as life-course persistent offenders (Boutwell, Barnes, \& Beaver, 2012). Most of the traffickers studied committed their first crime at a young age and mostly committed numerous (serious) crimes.

\subsection{Networks of traffickers}

Altogether, the findings of this study regarding the networks might provide further support for the presumptions that networks of domestic sex trafficking are less organized and less hierarchical structures than are present in cross-border sex trafficking (Van Dijke et al., 2015; Shively, 2017; Dutch Rapporteur, 2012; Boerman et al. 2017). The police and court files indicated that, when operating in networks, these networks comprised mostly a maximum of five persons. This was in line with an analysis of the Dutch Rapporteur (2014). Also, Van Dijke et al. (2015) and Hackett and Smith (2018) stated that most perpetrators operate alone or their networks are rather small. However organized, the networks of domestic sex traffickers in this study did not seemed to be as organized as networks of cross-border sex 


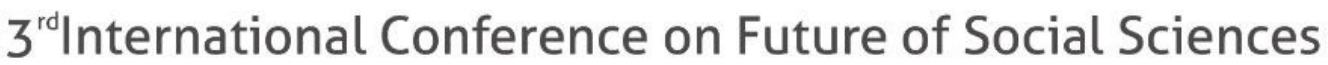 \\ 5 - 7 March 2021 \\ BERLIN, GERMANY}

trafficking, which are more often perceived as 'criminal organizations'. Most traffickers in this study that operated in networks for example exploited only one victim, traffickers had a rich criminal career with a diversity of convictions, and there were few recidivists among the traffickers. Also, consistent with a study of the Dutch Rapporteur (2014), most traffickers who operated in a network were involved in other criminal activities. This might imply that networks of domestic sex trafficking could be merely set up based on opportunity, rather than that these networks are organized around sex trafficking.

\subsection{A profile of domestic sex traffickers}

Based on a synthesis of the results, a profile of domestic sex traffickers could be provided. Sex traffickers - in general - are males with an age of around 25-30 years, who are born and raised in the Netherlands and mostly had a migration background. A substantial number of the traffickers are in a relationship and/or have children and are raised in disrupted families (and have in particular a poor relationship with their father). They have a low socio-economic status (low income, debts, no education) and a substantial number of the traffickers experienced negative childhood experiences and show problematic alcohol and drug use. As a result, they could develop narcissistic, antisocial or borderline traits. Most of the traffickers could be labeled as generalist and life-course persistent offenders, since they mostly have a long criminal record, with a diversity of (non-sexual) offences, starting from a young age. The traffickers either operated alone, or they operated in small-scale 'opportunistic' networks. These networks could be labeled as unstructured and non-hierarchical, and mostly based on social ties. Lastly, these networks do not seemed to be specialized in sex trafficking since most networks commit a diversity of criminal acts.

In this study, the motives of the traffickers could not be extracted from the police and court files. An earlier study pointed to financial gain as the most important motive (Rijken et al., 2015). The current study confirmed that the traffickers had a low socioeconomic status and found it hard to 'make ends meet' and thus financial gain could be considered as a motive. However, a few other possible mediators could be extracted that could be studied in more depth. For example, the role of psychological problems and psychopathy, caused by experiencing adverse childhood experiences or traumatic experiences later in life, could be considered as a possible instigator for involvement in sex trafficking - or committing sexual violence in general (Knight and Sims-Knight, 2003; Malamuth and Hald, 2016). Hackett and Smith (2018) suggested for example that the offending histories of perpetrators could indicate underlying pervasive antisocial behavior, leading to exploitative behavior through a pathway of antisocial thinking, one of the developmental pathways proposed by Ward and Siegert (2002). Another possible instigator for (re)offending is alcohol and drug related behavior. Alcohol and drug use could be related to socioeconomic status and psychological problems or directly be related to exploitation. Future research could further delineate the pathway from the adverse childhood experiences, socio-economic background and alcohol and drug related behavior to sex trafficking.

\subsection{Limitations}

A few limitations should be mentioned. A first methodological limitation lies in the selection of cases. Normally in case studies, a purposeful sampling strategy is used selecting either cases that are likely to replicate or extend a theory (theoretical sampling) or cases are 


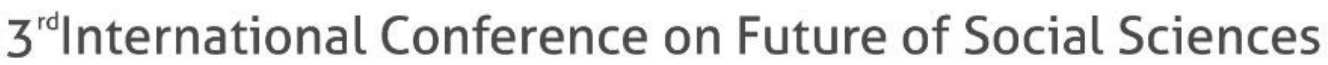 \\ 5 - 7 March 2021 \\ BERLIN, GERMANY}

selected based on the richness of their information (Ebneyamini and Moghadam, 2018). In this study however, a stratified (systematic) sampling strategy is applied. A limitation could be that by applying this strategy, there is no guarantee that a-typical, extreme or deviant cases were included gaining maximum variation and thus a full scope on the phenomenon. The rationale behind using a stratified (systematic) sampling strategy is, however, that the study sample is small, almost half of the cases that met the inclusion criteria could be included (25 out of 55). This increased the chances of maximum variation, without the researchers influencing the study results. A second limitation is that the reliability of some data sources (especially the statements of the traffickers, but also those of the victims) could be contradictory. Traffickers for example often deny their involvement (Shively et al. 2017; Copley, 2013; Van San and Bovenkerk, 2013; Van Dijke et al., 2015; Mehlman-Orozco, 2020), possibly as a strategy to prevent prosecution or reduce their sentence. Of victims, it is known that trauma can reduce the reliability of their memories and thus their statements (Klerx-van Mierlo, et al. 2014). Despite the possibility of reduced reliability, the statements of both traffickers and victims were an often used source in this study. By applying data and method triangulation, the reliability of these sources was enhanced. A third, and last, limitation is that intercoder reliability is not measured. The reason for this is that constructing the data sheet was a cyclical process where the data sheet was co-created using sensitizing concepts and preliminary discussion of the results. Several strategies were applied to enhance the intercoder reliability. First, the researchers constantly evaluated the cases and the sensitizing concepts in these cases. Second, by writing out or summarizing all relevant data, the chances of relevant data being missed were reduced.

\section{Conclusion}

The findings in this study related to the background and networks of sex traffickers supported and extended the knowledge out of previous studies. In general, most findings were (in general) compatible with previous studies and thereby strengthen the knowledge concerning domestic sex traffickers. This way, a detailed profile of domestic sex traffickers was provided. Based on the findings, indications appeared that domestic sex traffickers form a separate, distinguishable group of sex traffickers. This highlights the importance of considering them as distinct groups while studying sex traffickers.

\section{Acknowledgment (TNR 12pt. bold)}

This paper is an output of the science project...

\section{References}

Boerman, F., Grapendaal, M. Nieuwenhuis, F., \& Stoffers, E. (2017). Nationaal dreigingsbeeld 2014: Georganiseerde criminaliteit. Zoetermeer, The Netherlands: Dienst Landelijke Informatieorganisatie.

Boutwell, B.B., Barnes, J.C. \& Beaver, K.M. (2012). Life-Course Persistent Offenders and the Propensity to Commit Sexual Assault. Sexual Abuse, 25 (1), 69-81.

Constantinou, A.G. (2019). The roles and actions of sex traffickers in Cyprus: an overview. Trends in Organized Crime. published online. 


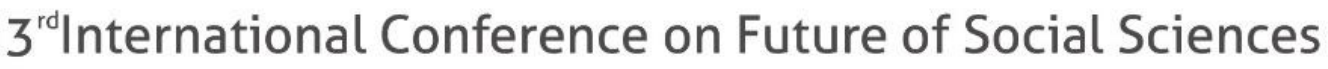 \\ 5 - 7 March 2021 \\ BERLIN, GERMANY}

Copley, L. (2013). Neutralizing Their Involvement: Sex Traffickers' Discourse Techniques. Feminist Criminology, 9 (1), 45-58.

Cresswell, J.W. (2007). Qualitative inquiry \& Research Design: Choosing among five approaches. California: Sage Publishings

Denzin, N.K. (2015). Triangulation. In: Ritzer, G. (ed). The Blackwell Encyclopedia of Sociology.doi:10.1002/9781405165518.wbeost050.pub2

Drummond, C. \& Southgate, J. (2018). Interventions for perpetrators of child sexual exploitation. A scoping study (report 4). Barkingside: Centre of Expertise on Child Sexual Abuse.

Dutch Rapporteur on Trafficking in Human Beings and Sexual Violence Against Children. (2012). Mensenhandel in en uit beeld. Cijfermatige rapportage 2007-2011. The Hague, The Netherlands: Author.

Dutch Rapporteur on Trafficking in Human Beings and Sexual Violence Against Children. (2014). Mensenhandel in en uit beeld II. Cijfermatige rapportage 2008-2012. The Hague, The Netherlands: Author.

Dutch Rapporteur on Trafficking in Human Beings and Sexual Violence Against Children. (2018). Slachtoffermonitor mensenhandel 2013 - 2017. The Hague, The Netherlands: Author.

Dutch Rapporteur on Trafficking in Human Beings and Sexual Violence Against Children. (2019a). Dadermonitor mensenhandel 2013-2017. The Hague, The Netherlands: Author.

Dutch Rapporteur on Trafficking in Human Beings and Sexual Violence Against Children. (2019b). Slachtoffermonitor mensenhandel 2014-2018. The Hague, The Netherlands: Author.

Ebneyamini, S., \& Moghadam, R.S.M. (2018). Toward Developing a Framework for Conducting Case Study Research. International Journal Of Qualitative Methods (17), $1-11$.

Gale, N.K., Heath, G., Cameron, E., Rashid, S., \& Redwood, S. (2013). Using the framework method for the analysis of qualitative data in multi-disciplinary health research. BMC Medical Research Methodology, 13

Hackett, S., \& Smits, S. (2018). Young people who engage in child sexual exploitation behaviors. Barkingside: Centre of Expertise on Child Sexual Abuse.

Hargreaves-Cormany, H.A., Patterson, T.D., \& Muirhead, Y.E. (2016). A Typology of Offenders Engaging in the Sex Trafficking of Juveniles (STJ); Implications for Risk Assessment. Aggression and Violent Behavior, 30, 40-47.

Klerx-van Mierlo, F., Youngs, D., Oostinga, M., Mergaerts, L., VanDale, D. \& Van der Velden, P. (2014). Treatment of traumatized victims of human trafficking to support coherent or consistent testimonies: An international explorative study. Tilburg: Intervict.

Knight, R.A., \& Sims-Knight, J.E. (2003). the developmental antecedents of sexual coercion against women: Testing alternative hypothesis with structural equation modeling. Annals of the New York Academy of Sciences, 989, 72-85. 


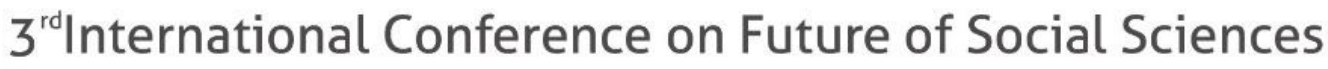 \\ 5 - 7 March 2021 \\ BERLIN, GERMANY}

Kragten-Heerdink, S.L.J., Dettmeijer-Vermeulen, C.E., \& Korf, D.J. (2017). More Than Just "Pushing and Pulling": Conceptualizing Identified Human Trafficking in the Netherlands. Crime and Delinquency, 1-25.

Malamuth, N.M. \& Hald, G.M. (2016). The confluence mediational model of sexual aggression. In: D. Boer (red.), The Wiley handbook of theories, assessment and treatment of sexual offending (pp.53-71). Chichester, UK: John Wiley \& Sons.

Mehlman-Orozco, K. (2020). Projected heroes and self-perceived manipulators: understanding the duplicitous identities of human traffickers. Trends in Organized Crime, 23 (2), 95-114.

Miccio-Fonsesca, L.C. (2017). Juvenile female sex traffickers. Aggression and Violent Behavior, 35, 26-32.

Patton, M. (1990). Qualitative evaluation and research methods. Beverly Hills, CA: Sage.

Reid, J.A. (2016). Entrapment and enmeshment schemes used by sex traffickers. Sexual abuse: A Journal of research and treatment, 28(6), pp. 491-511.

Reid, J.A., \& Fox, B. (2019). Profiles of Child Sex Traffickers: A Forensic Behavior Analysis. Human Trafficking Summit (2019). Available at: http://works.bepress.com/joan_reid/50/

Rijken, C., Muraszkiewicz, J., \& Ven, P. van de. (2015). Report on the features and incentives oftraffickers and on the social interactions among them. Trafficking as $A$ Criminal Enterprise (TRACE): Deliverable D3.1. Retrieved from: https://humantraffickingsearch.org/resource/report-on-the-features-and-incentives-oftraffickers-and-on-the-social-interactions-among-them/trace_deliverable-3-1_final-pdf/

Roe-Sepowitz, D.E., Gallagher, J., Risinger, M., \& Hickle, K. (2019). The Sexual Exploitation of Girls in the United States: The Role of Female Pimps. Journal of Interpersonal Violence, 30 (16), 2814-2830.

Roe-Sepowitz, D. (2019). A six-year analysis of sex traffickers of minors: exploring characteristics and sex trafficking patterns. Journal of Human Behavior in the Social Environment, 29 (5), 608-629.

Shively, M., Smith, K., Jalbert, S., \& Drucker, O. (2017). Human Trafficking Organizations and Facilitators: A Detailed Profile and Interviews with Convicted Traffickers in the United States. Online publication from National Institute of Justice. Retrieved from: https://nij.ojp.gov/library/publications/human-trafficking-organizations-and-facilitatorsdetailed-profile-and

Surtees, R. (2008). Traffickers and trafficking in Southern and Eastern Europe. European Journal of Criminology, 5, 39-68.

UNODC. (2014). Global Report on Trafficking in Persons. United Nations publication, No. E.14V.10. Retrieved from: https://www.unodc.org/documents/data-andanalysis/glotip/GLOTIP_2014_full_report.pdf

UN Palermo Protocol (2000). United Nations Protocol to Prevent, Suppress and Punish Trafficking in Human Beings, especially Women and Children, supplementing the UN Convention against Transnational Organised Crime. Retrieved from: https://www.ohchr.org/EN/ProfessionalInterest/Pages/ProtocolTraffickingInPersons.asp $\underline{X}$ 


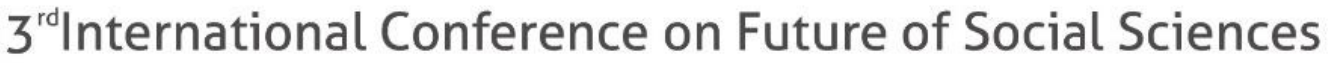

Van Dijke, A., de Ruiter, E., \& Terpstra, L. (2015). Mensenhandelaren: Verhalen en vonnissen. Amsterdam, The Netherlands. SWP Amsterdam.

Van Rij, J., \& McAlister, R. (2019). Using Criminal Routines and Techniques to Predict and Prevent the Sexual Exploitation of Eastern-European Women in Western Europe (16891708). In: Winterdijk, J., \& Jones, J. (eds). The Palgrave International Handbook of Human Trafficking. Palgrave Macmillan.

Van San., \& Bovenkerk, F. (2013). Secret seducers: True tales of pimps in the red light district of Amsterdam. Criminal Law Social Change, 60, 67-80.

Ward, T. and Siegert, R. (2002) Toward a comprehensive theory of child sexual abuse: A theory knitting perspective. Psychology, Crime \& Law, 8(4):319-351.

Wijkman, M.D.S., \& Kleemans, E.R.. (2019). Mensenhandel: De rol van vrouwelijke daders bij seksuele uitbuiting. Program Police and Science. Verkenningen $n r$. 84. Retrieved from:

https://www.politieenwetenschap.nl/publicatie/pw_verkenningen/2019/mensenhandel$\underline{327 /}$ 